\title{
A Study on a Reference Model of the Regional Innovation for the Hillside Road Towns
}

\author{
Taihun Lee ${ }^{\dagger}$ and Soon-Goo Hong * \\ *Dong-A University, Gudukro 225, Seo-Gu, Busan, 45236, South Korea \\ napsem@gmail.com,shong@dau.ac.kr
}

\begin{abstract}
In metropolitan cities, there exist regions that are left behind without a specific plan due to budget and administrative support limitations. In many cases, regional regeneration projects for these neglected regions are frustrated by an insufficient budget or difficulties of converging residents' needs. To solve problems in deteriorated regions, communication among diverse interested parties including administration, relevant companies, private organizations, and residents is required to understand problems and search for solutions. The purpose of this study is to develop a reference model for regional innovation using the case of Hocheon Village aiming at establishing collaborative relationships and finding a problem-solving method through communication. We defined the problem in Sanbokdoro Village as having many obstacles and suggested a reference model for which users facing similar problems can easily follow the entire process, including the solution process through a design thinking workshop opened in Hocheon Village and Corpus analysis. This study has academic contributions in that the extraction of key words based on TFIDF analysis gives a basis for establishing a system that can automatically analyze huge amounts of text data in the field of Corpus analysis involving a proceeding process that deals with regional problems.
\end{abstract}

Keywords: Co-creation, Design Thinking, Regional Innovation, Reference Model, Civil Engineering, Hillside Road Towns

\section{Introduction}

In metropolitan cities, there exist regions that are left behind without a specific plan due to budget and administrative support limitations. In many cases, regional regeneration projects for these neglected regions are frustrated by an insufficient budget or difficulties of converging residents' needs. To respond to the problem of regional regeneration where diverse interests are involved, policies that introduce the concept of governance have been recently introduced. Governance systems that presupposes collaboration between administrative organizations/government and residents/private organizations are producing innovative outcomes in terms of life-oriented welfare for residents and cost reductions. However, in a part of villages that have aging populations with diminished productivity and low regional accessibility, the capacity of private organizations alone cannot achieve regional innovation. In this case, sustainability should be guaranteed through diverse external collaborations. A methodology for regional regeneration is required that can create a driving force behind sustainable regional innovation through the

Received (May 21, 2017), Review Result (August 15, 2017), Accepted (September 11, 2017)

$\dagger *$ Corresponding author: Soon-Goo Hong, Professor

Management Information Systems

Dong-A University, Gudukro 225, Seo-Gu, Busan, 45236, South Korea

E-mail: napsem@gmail.com 
use of information technology (IT) and participation from multiple third parties.

When inducing participation from diverse interested parties including voluntary external participants, the process of conversation and communication that gets complicated due to multiple participants must be simplified. The purpose of this study is to develop a reference model for regional innovation that can solve the problem in the communication process by using new IT.

For the purpose of establishing a collaborative relationship that includes multiple external participants and searching for problem-solving method, we opened a design thinking workshop and conducted Corpus analysis targeting Hocheon Village as a subject. Using this method, we defined problems in Sanbokdoro Village, which has a number of obstacles, and suggested a reference model that covers the entire process including the solution process so that users can easily follow the model to solve similar problems.

\section{Concept of Co-Creation and the Necessity of a New Governance Regional Innovation Model}

An accurate understanding of the present condition of a problem that requires innovation and policy demands according to the diverse needs of citizens is the key to the policy's success. Even if the problem was properly understood in this way, unilateral policy generation by administration and experts cannot satisfy local residents, who are the consumers of the policy. As a result, "governance" or a "new governance" type is being pursued more and more where the opinions of local residents or many and unspecified citizens, interested organizations, a committee formed centered on the problem, and resident representatives are accepted through communication to produce solutions together.

Under a governance type based on "governance" in the past, collaboration between the administration and private sector tried to understand detailed problems one by one and respond to them. Meanwhile, a governance type based on IT innovation has its basis in IT, such as big data that can easily understand and predict consumers' demand. For example, an IT-based governance policy requires overall changes to policy generation that sensitively understand and predict demands regarding regional innovation problems and respond to them through new high-capacity data analysis and respond to the forecasted demands.

In terms of the development of governance structure, new governance that puts emphasis on transparent information and governance between private sector and government became a cornerstone for moving toward the governance structure in a cocreation concept. Co-creation-based governance accelerates the convergence of the existing governance structure through IT and makes it more sophisticated.

\section{Regional Innovation Model Based on Co-Creation}

Figure 1 depicts the regional innovation model based on co-creation as a reference model for deriving a problem-solving method. The regional innovation model based on co-creation has an organic form in which a co-creation-based online platform at the center shares information in the knowledge storage that contains various kinds of existing data [1]. 


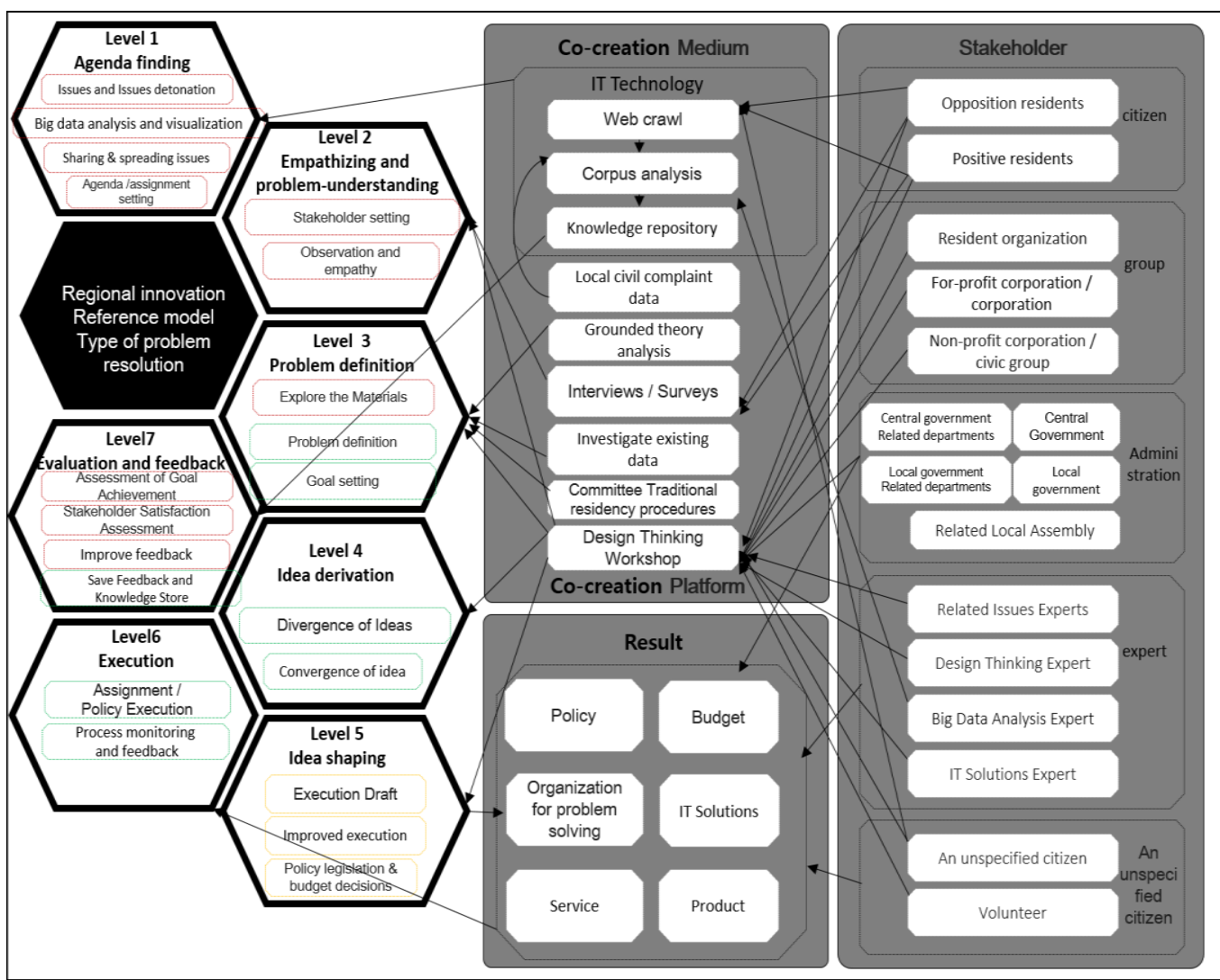

Figure 1. Regional Innovation Reference Model for Deriving a ProblemSolving Method

Table 1. presents a stage-by-stage description of Figure 1 that depicts the regional innovation reference model for deriving the problem-solving method as the concept model.

Table 1. Stage-by-Stage Description of the Regional Innovation Reference Model for Deriving the Problem-Solving Method

\begin{tabular}{|c|l|l|l|}
\hline Stage & \multicolumn{1}{|c|}{ Description } & Co-creation media & \multicolumn{1}{c|}{ Output } \\
\hline $\begin{array}{c}\text { Stage 1 } \\
\text { Agenda } \\
\text { finding }\end{array}$ & $\begin{array}{l}\text { - Detect regional innovation problems } \\
\text { that arise in the era of increasing } \\
\text { uncertainty using big data analysis } \\
\text { - Goal is to facilitate extensive } \\
\text { communication that includes all the } \\
\text { interested parties }\end{array}$ & $\begin{array}{l}\text { Web crawling, } \\
\text { Corpus analysis }\end{array}$ & $\begin{array}{l}\text { - Derivation of } \\
\text { policy issues }\end{array}$ \\
\hline $\begin{array}{c}\text { Stage 2 } \\
\text { anpathizing problem- } \\
\text { understanding }\end{array}$ & $\begin{array}{l}\text { - Set the range of interested parties. } \\
\text { - Perceive specific problems based on } \\
\text { their conversation and communication } \\
\text { and empathize with them to broaden } \\
\text { the level of understanding about the } \\
\text { problem }\end{array}$ & $\begin{array}{l}\text { Design thinking } \\
\text { workshop, } \\
\text { interview, survey, } \\
\text { the existing } \\
\text { residents' } \\
\text { participation } \\
\text { procedure }\end{array}$ & $\begin{array}{l}\text { - Setting of the } \\
\text { range of interested } \\
\text { parties } \\
\text { - Observation and } \\
\text { understanding about } \\
\text { the problem }\end{array}$ \\
\hline
\end{tabular}




\begin{tabular}{|c|l|l|l|}
\hline $\begin{array}{c}\text { Stage 3 } \\
\text { Problem } \\
\text { definition }\end{array}$ & $\begin{array}{l}\text { - Understand ceaselessly produced text } \\
\text { data, including interview data of } \\
\text { interested parties, meeting data, media } \\
\text { data on relevant issues, public hearing, } \\
\text { information session, and committee } \\
\text { data from an aspect of a type of } \\
\text { macroscopic conversation and } \\
\text { integrate them to define the problem }\end{array}$ & $\begin{array}{l}\text { Grounded theory } \\
\text { analysis, } \\
\text { corpus analysis }\end{array}$ & $\begin{array}{l}\text { - Problem definition } \\
\text { and goal setting for } \\
\text { solving the problem }\end{array}$ \\
$\begin{array}{c}\text { Stage 4 } \\
\text { Idea } \\
\text { derivation }\end{array}$ & $\begin{array}{l}\text { - Open a design thinking workshop for } \\
\text { interested parties who voluntarily want } \\
\text { to participate } \\
\text { - Release ideas for problem-solving } \\
\text { and converge them to summarize }\end{array}$ & $\begin{array}{l}\text { Design thinking } \\
\text { workshop }\end{array}$ & $\begin{array}{l}\text { - Convergence of } \\
\text { ideas }\end{array}$ \\
$\begin{array}{c}\text { Stage 5 } \\
\text { Idea shaping }\end{array}$ & $\begin{array}{l}\text { - Quick execution of a draft made } \\
\text { from the converged idea to determine } \\
\text { the improvement points }\end{array}$ & $\begin{array}{l}\text { Design thinking } \\
\text { workshop }\end{array}$ & $\begin{array}{l}\text { - Derivation of an } \\
\text { improved execution } \\
\text { draft }\end{array}$ \\
\hline $\begin{array}{c}\text { Stage 6 } \\
\text { Execution }\end{array}$ & $\begin{array}{l}\text { - Implement the policy or business } \\
\text { whose experimental execution was } \\
\text { tried and improved through the design } \\
\text { thinking workshop and execute it in } \\
\text { reality }\end{array}$ & $\begin{array}{l}\text { Output of the design } \\
\text { thinking workshop }\end{array}$ & $\begin{array}{l}\text { - Execution results } \\
\text { of the regional } \\
\text { innovation plan and } \\
\text { an improved } \\
\text { execution plan }\end{array}$ \\
$\begin{array}{c}\text { Stage 7 } \\
\text { Enaluation }\end{array}$ & $\begin{array}{l}\text { - Continuous improvement, rather than } \\
\text { fixed form, through monitoring and } \\
\text { feedback on the execution process } \\
\text { - Evaluate goal achievement and } \\
\text { satisfaction }\end{array}$ & Knowledge storage & $\begin{array}{l}\text { - Evaluation of goal } \\
\text { achievement } \\
\text { - Evaluation of } \\
\text { interested parties' } \\
\text { satisfaction }\end{array}$ \\
\hline
\end{tabular}

The regional innovation model in Figure 1 is a conceptual reference model aimed at improving regional innovation tasks through quick derivation and the execution of the problem-solving method.

Even if a new method was derived in a meeting in which many people participated, the application of new method always has an intrinsic risk of failure. Moreover, a new attempt requires time and money. The reference model is composed to minimize such risk, as the function of co-creation can spread risk through participation from diverse interested parties.

Even if the interested parties must bear a certain amount of risk and cost as of now, the co-creation process based on conversation and communication can reduce the cost of solving problem in the long-term by building trusting relationships.

\section{Case of Applying the Regional Innovation Reference Model to Sanbokdoro Village in Hocheon Village}

Hocheon Village is located in Sanbokdoro in Busan where a policy that resolves the regeneration problem by residents' participation has been implemented, which the administration alone could not address before. However, policies were often suspended not long after their initiation due to an insufficient budget and the problem of cultivating a workforce. In response to the problem, this study implemented a workshop that is centered on a resident committee and open to external participants and derived the output by applying a stage-by-stage procedure of problem-solving methodology aimed at solving regional problems.

Among Sanbokdoro's villages, some attract large numbers of tourists by receiving a great deal of attention from media and administration, such as Gamcheon Culture Village and Anchang Village. On the other hand, there are many more ordinary villages that gradually deteriorate without receiving people's attention like the subject of this study, Hocheon Village. These Sanbokdoro villages have inferior accessibility to town and city 
infrastructure. There are regions that have poor gas, parking facilities, fire lanes, hospitals, school, and even water supplies and drainage facilities. The resident composition also gradually changes, such that economically and socially poor people occupy the majority. In this situation, it is realistically hard to expect that the application of the ordinary urban development regional innovation model can attain regional innovation.

We applied a reference model process for deriving the problem-solving method as shown in Figure 1 to Hocheon Village, which is one of the Sanbokdoro villages in Busan. The problem of deterioration in the region surrounding Sanbokdoro is an issue of regional innovation that has long history in Busan.

\subsection{Stage 1: Agenda Finding}

The regeneration of Sanbokdoro's village is one of the issues that have been shared and spread among citizens in Busan for a long time. In Stage 1 of the agenda finding, we conducted an examination process of the village that receives relatively little attention among Sanbokdoro's villages and proposed a solution for regional innovation problems through a design thinking workshop in agreement with the Hocheon Village resident committee located in Beomjeon-dong, Jin-gu, Busan.

\subsection{Stage 2: Design Thinking Process for Empathizing and Problem-Understanding}

Based on the design thinking methodology, we opened a workshop for village residents and external participants aiming at searching for a sustainable village regeneration method through co-creation by diverse interested parties, including external participants interested in regional innovation, residents, local administration, and experts in regional regeneration.

For Stage 2, empathizing and problem-understanding, interested parties were defined and a workshop team was composed, as shown in Table 2. The workshop was implemented by dividing the participants into five teams. Two teams were formed under the theme of the derivation of the regional innovation problem in Hocheon Village, and two teams were formed under the theme of new business design for regional vitalization. Finally, one team was formed under the theme of product design that will be manufactured by village company. When forming teams, two out of five teams underwent a different procedure than design thinking for the purpose of obtaining comparison data that can be used to understand the effectiveness and pros and cons of design thinking that this study attempts to test and find its improvement point in terms of empathizing and problem-understanding. The two groups worked on the same theme in the same place during the same time period, but followed a general idea meeting procedure instead of a method that applies design thinking.

Table 2. Workshop Participants and Team Composition

\begin{tabular}{|c|c|c|}
\hline Team & Outcome & Team composition \\
\hline Team 1 & $\begin{array}{l}\text { Regional vitalization project, } \\
\text { creation of the application }\end{array}$ & $\begin{array}{l}\text { facilitator, village resident } 1 \text {, village resident } 2 \text {, external } \\
\text { participant, IT expert }\end{array}$ \\
\hline Team 2 & $\begin{array}{l}\text { Creation of a regional } \\
\text { problem-solving website }\end{array}$ & $\begin{array}{l}\text { facilitator, village resident } 1 \text {, village resident 2, external } \\
\text { participant, IT expert }\end{array}$ \\
\hline Team 3 & $\begin{array}{l}\text { Regional vitalization project, } \\
\text { creation of the application }\end{array}$ & $\begin{array}{l}\text { regional regeneration expert, village resident } 1 \text {, village } \\
\text { resident } 2 \text {, external participant, IT expert }\end{array}$ \\
\hline Team 4 & $\begin{array}{l}\text { Creation of the regional } \\
\text { problem-solving website }\end{array}$ & $\begin{array}{l}\text { regional regeneration expert, village resident } 1 \text {, village } \\
\text { resident } 2 \text {, external participant, IT expert }\end{array}$ \\
\hline Team 5 & $\begin{array}{l}\text { Village company, product } \\
\text { design }\end{array}$ & $\begin{array}{c}\text { facilitator, regional regeneration expert, village resident } 1 \text {, } \\
\text { village resident } 2 \text {, external participant, designer }\end{array}$ \\
\hline
\end{tabular}

The workshop in Hocheon Village was held at the Hocheon Life Culture Center for 12 hours from 9 am to $9 \mathrm{pm}$ on 29th in 2016, where a total of 30 members participated, 
including 10 village residents, three local activists, 10 external participants, and seven facilitators.

Three goals were set, including improvements in village inconveniences, contents made by village companies, and the identification of a village regeneration business. The participants were divided into three design thinking teams; a trained facilitator led one team, and two regular brainstorming teams had no facilitator. The facilitator received training from the design thinking workshop. Local activists were experts in regional regeneration who received training for village-making activity run by Busan City.

Design thinking is a creative problem-solving methodology that searches for solutions to a problem through the combination of intuitive and analytical thinking. The concept of design used here refers to a broader range of design than the concept that pursues aesthetic beauty or superficial sophistication. It means process of accurately perceiving a certain problem at present and deriving desired outcome (Hyeong, 2016). Three design thinking groups went over the following five-stage procedure in which a trained facilitator coordinated the proceeding of the participants.

1. Empathize: understand insight (hidden needs) through observations and interviews

2. Define: define the real problem by summarizing the outcome from the empathize stage and set the coverage.

3. Ideate: search for method that can solve the detected problem

4. Prototype: fabricate the visualized prototype for problem-solving

5. Test: test the manufactured prototype in the market

The Empathize, Define, and Ideate process progressed over six hours from 9 am to 3 $\mathrm{pm}$ and conversations that took place during this process were recorded.

In the case of the two general brainstorming groups without a trained facilitator, a presenter and clerk were chosen within each team, and they worked on brainstorming for the problem assessment and solution derivation over six hours from 9 am to $3 \mathrm{pm}$. Similarly, conversations during this process were recorded. After, all five teams worked on manufacturing and testing prototypes based on the derived plans for six hours from 3 pm to $9 \mathrm{pm}$.

\subsection{Stage 3: Definition of Problem Through Interviews}

In Stage 3, a process of defining problems through communication and conversation is required. Problems can be defined by summarizing macroscopic conversations taking place among diverse interested parties in a complex way. Text data that are ceaselessly being produced, including interview data of interested parties, meeting data, media data regarding the relevant issues, public hearings, information sessions, and committee data, can be thought of as a kind of macroscopic conversation. As such, we implemented a qualitative analysis using collectable text data. By understanding the context of the regional problem and the causal relationship based on the grounded theory analysis, we can clarify the core of the problem. As the interested parties approach the core of the regional problem together, clear goals can be set in this problem definition process.

The discussion from $9 \mathrm{Am}$ to $3 \mathrm{Pm}$ during the workshop was recorded and stored in a text file by typing. The qualitative study was implemented using the deposition text written based on the residents' voices. As a specific method of qualitative research, we went over the process of the coding, saturation, sampling, and conceptualization of the grounded theory to closely investigate the empathizing and problem-definition process. As a result, problems were defined, as listed below.

1) Residents' participation rate is low, and they are passive. As a result, a variety of activities by the resident committee are often one-time events, being unable to continue for long.

2) Physical accessibility is low due to the geographic characteristics of Sanbokdoro. Because of narrow roads, there is a potential risk of difficult responses to disasters, 
such as fires.

3) Most of the residents are older, and their income is insufficient.

4) Independence is required such that power inside the village can run regional regeneration activity.

5) It is necessary to attempt village vitalization using culture platform.

6) Village promotion efforts that use IT should accompany village promotion in reality.

7) Developing a tourist spot is necessary for content development, like Gamcheon Culture Village.

8) Diverse viewpoints and collaboration are required, such as the current design thinking workshop.

9) Despite its ordinary look, Sanbokdoro Village has valuable features such as an excellent nightlife, view, and sequestered atmosphere.

10) Village residents' perception of our village is gradually changing through the current activity.

11) There are not enough contents exclusive for Hocheon Village.

\subsection{Stage 4: Idea Release and Convergence Process Analysis}

We conducted a Corpus analysis using the text file that recorded conversations during the process of idea derivation and execution plan writing. We implemented the preprocessing of sentences through the morphological analysis of the text file and extracted key words from the conversations that changed over time through time-series TFIDF analysis. Through these analyses, we attempted to determine implications regarding the core problem in the region and the problem-solving process based on design thinking that was tested in this study.

Table 3. Top 15 TFIDF Values

\begin{tabular}{|l|c|c|c|c|c|c|c|c|c|c|}
\hline & \multicolumn{2}{|c|}{ Team 1 } & \multicolumn{2}{c|}{ Team 2 } & \multicolumn{2}{c|}{ Team 3 } & \multicolumn{2}{c|}{ Team 4 } & \multicolumn{2}{c|}{ Team 5 } \\
\hline & word & TFIDF & word & TFIDF & word & TFIDF & word & TFIDF & word & TFIDF \\
\hline $\mathbf{1}$ & Tourist & 113 & Facility & 50 & Person & 54 & Ward office & 49 & Unique color & 52 \\
\hline $\mathbf{2}$ & Gamcheon & 37 & Business & 45 & Use & 50 & Platform & 45 & Communication & 48 \\
\hline $\mathbf{3}$ & Serenity & 23 & Word & 27 & Platform & 45 & Cat & 40 & Product & 37 \\
\hline $\mathbf{4}$ & Hocheon & 22 & Use & 27 & Experience & 42 & Ghost & 40 & Move-in & 33 \\
\hline $\mathbf{5}$ & Activity & 20 & Activity & 27 & Space & 38 & Road & 34 & Tiger & 32 \\
\hline $\mathbf{6}$ & Concentration & 20 & Satisfaction & 26 & Inconvenience & 37 & Tourist & 34 & Privacy & 29 \\
\hline $\mathbf{7}$ & Contents & 38 & Age & 25 & Rubber shoes & 37 & Activity & 34 & Aged person & 20 \\
\hline $\mathbf{8}$ & Age & 19 & Outside & 24 & Exhibition & 35 & woman & 30 & Hocheon & 19 \\
\hline $\mathbf{9}$ & Person & 19 & Page & 22 & Business & 35 & Parking & 29 & Invasion & 19 \\
\hline $\mathbf{1 0}$ & Fairy tale & 17 & Public health center & 20 & Street & 35 & Outside & 28 & Parking & 17 \\
\hline $\mathbf{1 1}$ & Region & 16 & Proceeding & 28 & Sales & 33 & Play & 28 & Tourist & 17 \\
\hline $\mathbf{1 2}$ & Culture & 15 & Tiger & 19 & Artist & 31 & Event & 28 & Business & 16 \\
\hline $\mathbf{1 3}$ & Unique color & 15 & Exercise & 19 & Culture & 30 & Participation & 25 & Restriction & 15 \\
\hline $\mathbf{1 4}$ & Platform & 15 & Participation & 18 & Aged person & 25 & Support & 25 & Item & 15 \\
\hline $\mathbf{1 5}$ & Promotion & 13 & Web & 18 & House & 25 & $\begin{array}{c}\text { Each } \\
\text { individual }\end{array}$ & 24 & $\begin{array}{c}\text { Elementary } \\
\text { school student }\end{array}$ & 15 \\
\hline
\end{tabular}

Expressions that were typically used in the workshop including question, member, response, words, interview, residents, thoughts, problem, sentence, proceeding, and other meaningless nouns as well as village, vitalization, and method that are related to the theme of the workshop were excluded from the analysis.

Tourists, business, platform, and activity were commonly included in three teams. Hocheon, tiger, age, people, culture, participation, outside, parking, aged person, and unique color were commonly included in two teams. There were words that express emotions, such as serenity, concentration, satisfaction, inconvenience, invasion, and 
restriction.

The name of the village "Hocheon" was proven to be an important keyword, which was heavily mentioned in all teams except for team 3. The appearance of this key word was linked to the tendency of excessively focusing on the name "Hocheon Village" when thinking about the content production for local commercialization. Attempts to link to "tiger," "Hogyecheon", or "Hocheon" also have this problem. As for business type, the business plan centered at the Hocheon culture platform installed at the top floor of a newly built public parking lot was at the core. We could confirm that most of the participants were perceiving the platform as a strong business tool for this village. The workshop participants that had a high participation rate expressed their regret for the residents with a low participation rate. They tried to increase residents' participation rate and gain attention from outside regions by promoting their activity.

\subsection{Stage 5: Idea Shaping}

This is a stage that creates an execution draft for the ideas that came from the workshop and attempts to implement them. The execution draft can be a self-contained policy plan or a form that does not have an output yet. Quick execution is strongly emphasized. As the execution draft, two Android-based applications, two websites, and one proposal for manufacturing the village company products were derived.

A culture experience class on the top floor of a Hocheon Village public parking lot and a life culture platform activation plan for product sales were derived. Specifically, a rubber shoes project was derived in team 3. A product plan was proposed in which pictures and tigers, which represent the image of Hocheon Village, are drawn on rubber shoes.

Team 4 discussed a tea-selling project in the platform. In the proposed system, residents who are interested in tea voluntarily work as sellers, and they are fairly distributed in proportion to their working amount when profit occurs. Ideas for specific menus that introduce the image of Hocheon Village in tea sales were derived, including an "herb tea that gives tiger-like energy" and "dried-persimmon tea that even tiger is afraid of." The derived execution plan underwent an improvement process as other team members in the workshop tried and evaluated the ideas.

In the workshop process, ideas were derived focusing on the possibility of quick execution. Hence, most of the derived plans were small and focused on the system improvement in a small range. However, the idea for a profit distribution system for tea sellers in the Hocheon Culture platform and the idea for the products that can be mass produced have significance in that they can be linked to large-scale policy in the future.

\subsection{Stage 6: Execution}

Stage 6 is a stage of executing the improved draft in reality through quick implementation and modification. In the execution stage, legal support or a budget is required in the case of policy, and a sustainable system and budget is required in the case of private business. Hence, the project must either receive support from the administration, or gather participants or investors. The output of the design thinking workshop process can be used as political grounds for persuading other interested parties to participate in the system's establishment and contribute to a certain amount of the budget. In the case of Hocheon Village, an increase in the sales of rubber shoes that was proposed in the execution draft and popularity gains of the cultural lecture in the platform are being suggested as persuasive grounds for business expansion.

\subsection{Stage 7: Evaluation and Feedback}

The stage of evaluation and feedback evaluates whether the goal that was set in Stage 3 
was attained. Here, the interested parties' satisfaction should be evaluated. Using knowledge storage as a platform, the satisfaction and opinions for improvement of the interested parties are collected.

\section{Conclusion}

There are many small and large issues inside any region. To solve these problems, an understanding of the problem through communication among diverse interested parties including administration, relevant companies, private organizations, and residents is essential.

In Hocheon Village in Sanbokdoro, Busan, residents have made efforts to solve regeneration problems through their participation, which previously could not be resolved by the intervention from the administration. However, these efforts were frequently suspended not long after their initiation due to an insufficient budget and the problem of cultivating a workforce. To respond to these problems, this study hosted a workshop centered on the resident committee and opened it to external participants. We derived a regional innovation reference model that Sanbokdoro Village can follow by applying a stage-by-stage procedure of the methodology regarding regional problem solving.

This study has academic contributions in the field of Corpus analysis for analyzing the process and proceedings of meetings dealing with regional problems in that it used the extraction of key words through Korean national language processing technology and TFIDF analysis as a methodology. These methods provide the basis for establishing a system that can automatically analyze huge amounts of text. The study also has practical contributions in the field of regional innovation. First, we worked on co-creation with external participants over the course of searching for realistic plans to overcome the problem of stagnant regional innovation in Hocheon Village. Second, we derived a realistically usable application and product draft.

This study has also several limitations. We formed two control teams as a comparison group and collected meeting data to derive improvement point of design thinking. However, it was difficult to completely satisfy the control condition of the comparison group due to differences in the team composition stemming from the differences in their age, sex, and ability and different proceeding processes. Moreover, continuous implementation of the workshops will be required to assess the sustainability of the regional innovation.

\section{Acknowledgments}

This work was supported by the Ministry of Education of the Republic of Korea and the National Research Foundation of Korea (NRF-2015S1A3A2046781).

\section{References}

[1] S. G. Hong, S. H. Park, Y. S. Cha and N. R. Kim, "Implementation Procedures and Methods of Cocreation", The Journal of Internet Electronic Commerce, vol. 14, no. 1, (2014), pp. 89-106

[2] W. J. Hyeong, "Design Thinking TTT", SAP Korea, (2016).

[3] "The Hochun Town Meeting and Dong-eui University", The Hochun Town Archives "The Hochun Town Story", Busan Town Planning Support Center, Community Capacity Strengthening Projects, (2015).

[4] H. Jeong, K. Kobayashi, K. Hatori and S. Shiramatsu, "Facet Decomposition and Discourse Analysis of Public Debate", Journal of Japan Society of Civil Engineers, Ser. F, vol. 66, no. 1, (2010), pp. 45-56.

[5] H. Jeong, S. Shiramatsu, K. Kobayashi and T. Hatori, "Discourse Analysis of Public Debates Using Corpus Inguistic Methodologies”, Journal of Computers, vol. 3, no. 8, (2008), pp. 58-68. 
International Journal of $u$ - and e- Service, Science and Technology Vol.10, No.9 (2017) 